\title{
GRNN-Immune Based Strategy for Estimating and Optimizing the Vibratory Assisted Welding Parameters to Produce Quality Welded Joints
}

\author{
P. Govinda Rao ${ }^{1, a^{*}}$, P. Srinivasa Rao ${ }^{2, b}$, and B. B. V. L. Deepak ${ }^{3, c}$ \\ 1 Department of Mechanical Engineering, GMR Institute of Technology, Rajam, Andhra Pradesh, India \\ 2 Department of Mechanical engineering, Centurion University, Parlakhemundi, Odisha, India \\ 3 Department of Industrial Design, National Institute of Technology, Rourkela, Odisha, India \\ E-mail: agovind09.p@gmail.com, (Corresponding author), bpsrao89@gmail.com, cdeepak.bbvl@gmil.com
}

\begin{abstract}
Welding is the process of producing permanent joints with the application of pressure and/or heat energy. During welding operation, weldments may be subjected to uneven thermal stresses. These stresses influence the metallurgical structure of the component. Due to this, the strength of the weld joint is reduced. Therefore, vibratory weld treatment during welding has been proposed in the present work to enhance the flexural and impact strength of weldments. However, it is found that the mechanical properties have shown nonlinear behavior with the chosen input parameters. Hence, an efficient Neural Network (NN) based prediction tool is developed to approximate the mechanical properties of weldments without performing the experiments, output values can be predicted for the given input values. Further, an immune based strategy is integrated to the developed prediction tool in order to obtain desired quality welded joints.
\end{abstract}

Keywords: Welding process, mechanical vibrations, metallurgical properties, mechanical properties, plastic deformation, neural network and immune system.

ENGINEERING JOURNAL Volume 21 Issue 3

Received 14 September 2016

Accepted 3 November 2016

Published 15 June 2017

Online at http://www.engj.org/

DOI:10.4186/ej.2017.21.3.251 


\section{Introduction}

Welding is one among the different fabrication processes used in industries for joining materials. Welding procedure involves joining of the material pieces by melting them at the joining interface with addition of filler material [1].But the welding operation causes residual stresses in the welded joints because of involvement of heat energy. Due to this, strength of the weld joint is reduced.

To overcome this issue, different methods have been proposed in the past to improve the mechanical properties of welded joints. These methods are described below.

\subsection{Effect of Post Weld Heat Treatment (PWHT)}

Post Weld Heat Treatment is one type of heat treatment process applied to welded joints after completion of the welding process. PWHT improves the mechanical properties and reduce the brittle fracture of welded joints by changing the metallurgical structure.

Ding et al. [2] adopted PWHT method to the welded joints to improve the properties of the welded joints for Tungsten Inert Gas (TIG) welded AA2219 aluminium alloy joints. Ahmed et al. [3] investigated PWHT at high temperatures and different soaking times to improve the tensile strength and impact strength of welded joints. They applied PWHT to Cr-Mo Boiler Steel Welded with Shielded Metal Arc Welding (SMAW) Process. Ibrahim et al. [4] found that the PWHT with quenching in neem oil and improved the tensile strength and hardness of welded joints compared to quenching in engine oil. Ahmad et al. [5] applied PWHT for AA6661 welded joint to enhance tensile strength and hardness compared with as-welded joint. Increase in tensile and hardness of PWHT joint is 3.8\% and $25.6 \%$ respectively. This is due to the fine grain structure and small gap between the grains occurred at the weld zone, which was captured by SEM factographs. Zhu et al. [6] found that tensile strength of AA2219 aluminium alloy TIG welded joint was significantly increased by PWHT compared to as-weld condition. Smith et al. [7] observed an improvement in impact toughness for multi pass submerged arc welded joint of pressure vessel steel. However, there is a decrement in hardness and transverse weld strength. Badji et al. [8] found that there is a significant improvement in micro-hardness of TIG welded 2205 duplex stainless steel by PWHT.

\subsection{Effect of Pulsed Current}

In pulsed current welding, the welding current will be pulsed at the time of operation. This is developed for controlling metal transfer at low mean current levels by imposing short duration high current pulses to improve the mechanical properties of weldments.

Mao et al. [9] observed that the hardness, tensile strength and ductility have been enhanced in the Pulsed Current Gas Tungsten Weld (PCGTW) joints compared to non-pulsed current welding. Sawanishi et al. [10] found a perfection in tensile strength of spot welded joint produced with pulsed current from 7 to $11 \mathrm{kN}$. Balasubramanian et al. [11] performed welding process to make the joints with incessant current GTAW, pulsed current GTAW, and combination of these two for high strength aluminium alloys. Pulsed current welding in both GTAW and GMAW leads to increase in tensile strength, when compared to conventional continuous current welding. This is due to the fine grain structure attained in pulsed current welding. Manikandan et al. [12] observed an improvement in tensile strength of welded joints is achieved in both autogenous and with filler wire, when compared to non-pulsed current welding. Ravindra et al. [13] found that there is an improvement in hardness of welded joints produced with pulsed current compared to non-pulsed current TIG welding. In the meanwhile, they observed tensile strength was decreased with pulsed current compared to non-pulsed current.

\subsection{Effect of Hybrid Welding}

Hybrid welding is another way of improving the mechanical properties of weldments. It is a type of welding process that combines the principles of one type of welding to another type of welding to enhance the properties of weldments. There are mainly three types of hybrid welding processes depending on the arc used. Those are TIG-laser welding, plasma arc-laser welding and MIG augmented-laser welding. Among these, MIG-laser hybrid welding has been entered into industrial applications, even though first research work was carried on TIG-augmented laser welding. 
Dai et al. [14] applied the Gas Tungsten Arc Welding (GTAW) assisted hybrid ultrasonic seam welding for improving the tensile \& shear strengths of welded joints. Leo et al. [15] investigated that, if the welding voltage and current are decreased, tensile strength and micro-hardness are increased. In this investigation, hybrid laser-arc welding was done on Al-Mg alloy welded joint. Li et al. [16] found that shear strength of Tjoints was improved by $90 \%$ of base metal in hybrid welding of laser-GTAW, as compared to joints produced only with laser welding or gas tungsten arc welding (GTAW).

\subsection{Drawbacks in PWHT, Pulsed Current Welding and Hybrid Welding}

Despite the above methods are used widely in practice, they have certain drawbacks.

- For instance, Post Weld Heat treatment (PWHT) requires special tools and consumes more time, when compared with the remaining methods.

- High pulsed current reduce mechanical properties of welded joints compared to low pulsed current. If the thickness of sheets is increased, mechanical properties have been reduced in pulsed current welding.

- In hybrid welding, a large number of parameters should be carefully adjusted; otherwise this may lead to reduce the strength of the joint.

\subsection{Vibratory Welding}

To overcome the above drawbacks, a vibratory setup is introduced to enhance the mechanical properties of weldments. In this process, mechanical vibrations are given to the weldments with periodical force during the welding operation [17]. Compared to above said techniques, vibratory assisted welding has advantages such as economic, flexibility in use, pollution free and less manufacturing time [18]. Due to these special characteristics, vibratory welding techniques have been implemented effectively with varying degree of success [19-21]. Even though, the effect of vibratory parameters on mechanical properties of weldments is still a remaining question mark to the researchers. Dynamic solidification technique during welding has been proposed to prompt the mechanical vibrations during welding of butt welded joints. It was presumed that butt welded joints arranged under vibratory conditions had high hardness with no loss of its ductility. Authors utilized the vibratory setup to affect the mechanical vibrations to the weld pool amid welding. Because of vibratory welding process, change of mechanical properties has been observed. It was inferred that the refined microstructure component was in charge of the change of impact strength, tensile strength, flexural strength and hardness of butt welded joints of mild steel plates. Authors observed that post weld vibratory treatment will not influence the crystal structure, the increase in all properties are related to the crystal structure only. Finally, General regression neural network technique (GRNN) based tool has been developed for estimating tensile strength, impact strength, flexural strength and hardness for given input parameters [22-29].

Overcome the disadvantages of the stated above, a vibratory set up have been developed in the current investigation to enrich the mechanical properties of welded joints with the following objectives:

- To introduce the effect of magnitude and time of vibrations in order to enhance the mechanical properties of welded joints.

- To find the behavior of weld joint mechanical properties with respect to vibration parameters.

- To develop the prediction tool in order to relay the vibration parameters and weld joint mechanical properties using Generalized Regression Neural Network (GRNN).

- To optimize the GRNN relation using artificial immune system.

\section{Vibratory Welding Equipment Setup}

To mount the workpiece, a platform is prepared with four springs at each corner. The developed vibration setup in this investigation is equipped with a vibromotor to the vibration table set. Several accessories are fixed to the vibromotor to produce the vibrations. Figure 1 shows the photograph of the experimental setup. The measurement of vibration parameters are done using the magnetic pickup of the vibration tester. 


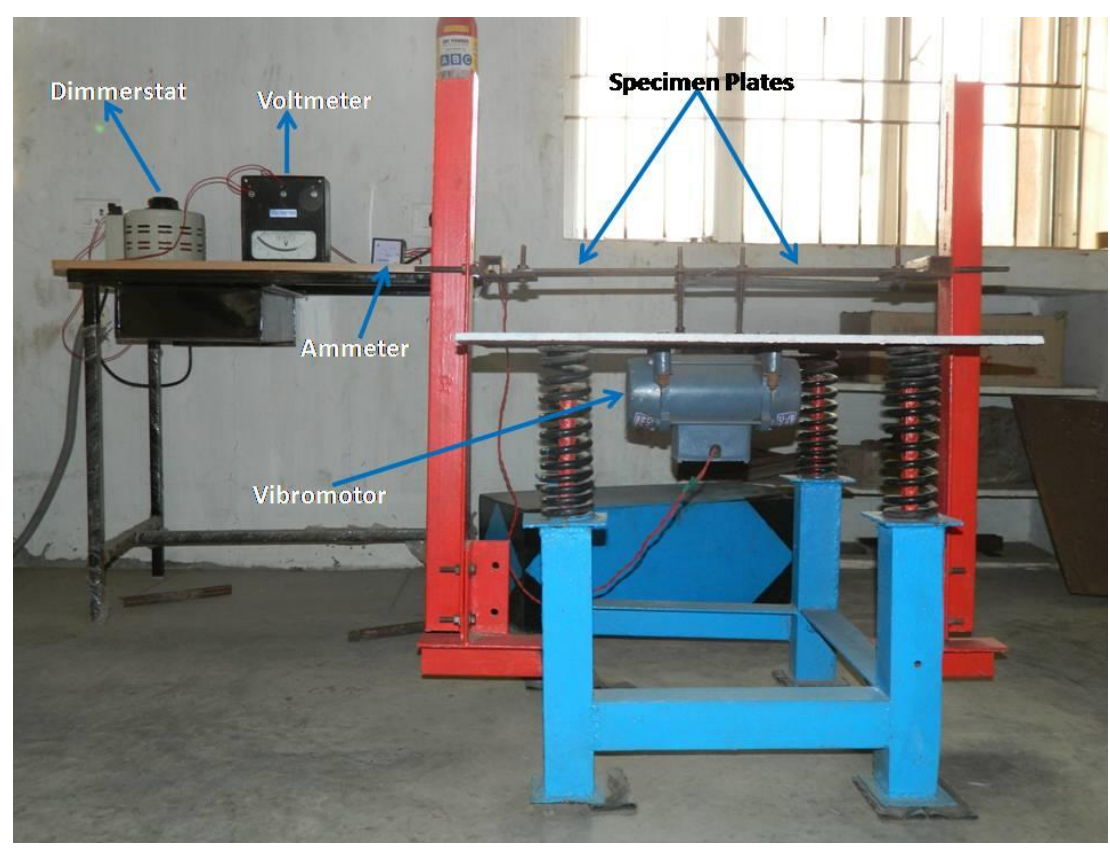

Fig. 1. Vibratory welding equipment setup.

Experiments have been conducted at different frequencies with different amplitudes in terms of voltages of vibromotor. To produce the sympathetic grain structure of the welded joints, the induced mechanical vibrations are applied along the weld seam. The developed system generates the wanted mechanical vibrations at desired frequency and amplitude in terms of voltages.

\subsection{Weld Joint Preparation}

In this investigation, manual metal arc welding procedure is followed to produce the weld joints and mild steel is considered for analysis. Steel plates with dimensions of $300 \times 100 \times 5 \mathrm{~mm}$. are mounted on the vibration platform, then the setup is activated by supplying the power. Filler metal ER4111 is used for the welding operation. Filler metal (ER4111) composed of (in weight percentage) maximum of 0.12 Carbon (C), $0.30-0.60 \%$ manganese $(\mathrm{Mn}), 0.40 \%$ Silicon $(\mathrm{Si})$, maximum of $0.04 \%$ Phosphorus $(\mathrm{P})$, maximum of $0.04 \%$ Sulphur(S)and the base metal Iron $(\mathrm{Fe})$ is used.

Mild Steel of $5 \mathrm{~mm}$ thickness plates are considered in the present study having the composition of $0.3 \%$ Carbon (C), 7.5-10.0\% manganese (Mn), 1.00\% Silicon (Si), 17.0-19.0\% Chromium (Cr), 4.0-6.0\% Nickel $(\mathrm{Ni}), 0.06 \%$ Phosphorus $(\mathrm{P}), 0.03 \%$ Sulphur $(\mathrm{S})$, and the base metal Iron $(\mathrm{Fe})$. Figure 2 shows the dimensions of mild steel plates to be welded with the root depth of $0.3 \mathrm{~mm}$.

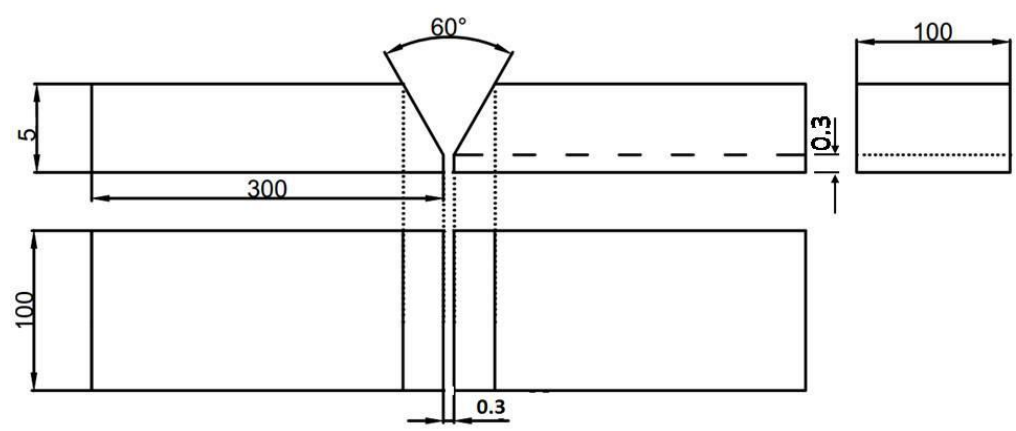

Fig. 2. Dimensions of mild steel plates to be welded. 
In the arc welding chosen there are several parameters to affect the weld strength. Such main process parameters are voltage, current, weld travel speed, electrode size, and spark gap which are fixed as $23 \mathrm{~V}$, $100 \mathrm{~A}, 0.35 \mathrm{~mm} / \mathrm{sec}, 3.15 \mathrm{~mm}$ dia. and $3 \mathrm{~mm}$. respectively.

\subsection{Vibratory Weld Parameters}

In present work, the set of vibratory parameters viz., voltage of vibromotor and time of vibration are considered for investigation.

Time of vibration refers to the time for which specimens have been vibrated during welding. Time of vibration is restricted up to 100 seconds at each voltage of vibromotor, because in Arc welding process for mild steel, the temperature $2500^{\circ} \mathrm{C}$ is the average highest weld pool temperature and mild steel crystallizes at $540^{\circ} \mathrm{C}$ according to phase diagram of mild steel. Falling temperature from $2500^{\circ} \mathrm{C}$ to $540^{\circ} \mathrm{C}$ has been observed by "Digital Infrared Thermometer" and also average time taken to reach $540^{\circ} \mathrm{C}$ from $2500^{\circ} \mathrm{C}$ was measured as 100 seconds with stop watch. After crystallization, improvements in mechanical properties of welded joints are negligible. Hence the time of vibration was restricted up to 100 seconds.

Voltage of vibromotor was restricted up to 250 Volts. When the voltage of vibromotor crosses 250 volts, the amplitude of vibrations generated by the voltage exceeds $0.5 \mathrm{~mm}$ making the spark gap more than $3 \mathrm{~mm}$. In such condition, welding is not possible and hence the higher bound for the voltage is fixed at 250 volts. With regard to the lower bound, Vibromotor does not work at a voltage which is $<50$, because of this; the minimum voltage for vibromotor is set to 50 volts.

Total 63 number of specimen are prepared at voltage from 50-250 with an interval of $10 \mathrm{~V}$ and at vibration period of 60,80 and $100 \mathrm{sec}$. at each voltage.

\section{Experimental Results}

For the prepared welded joints metallurgical and mechanical properties have been analysed through various tests.

\subsection{Variation in Metallurgical Properties}

A detailed Metallurgical analysis has been performed in [19, 20]. From the micro structural evolution it has been found that grain refinement occurs during random vibrations process. Average grain size numbers have been investigated by image analyzer software and average diameters of grains have been found according to ASTM E 112-96. The grain sizes of welded zones at without vibration condition and at different voltages of vibromotor have been listed in Table 1.

Table 1. Grain sizes of welded zones at different voltages of vibromotor.

\begin{tabular}{lccc}
\hline S.No. & Voltage of Vibromotor(Volts) & Average Grain size Number & Average Diameter of Grain $(\mu \mathrm{m})$ \\
\hline 1 & Without Vibration $(0 \mathrm{~V})$ & 8 & 22.5 \\
2 & $70 \mathrm{~V}$ & 9 & 15.9 \\
3 & $150 \mathrm{~V}$ & 10 & 11.2 \\
4 & $230 \mathrm{~V}$ & 11 & 7.9 \\
\hline
\end{tabular}

The vibration energy worked on the refinement of grains during the solidification of the fillet metal in the welded zone. However, the $230 \mathrm{~V}$ resulted in the more fine grain structure compared to vibration at $70 \mathrm{~V}$, $150 \mathrm{~V}$, and without vibration condition. Also, better fusion of fillet metal distribution in the weld zone is observed with respect to increase in voltage of vibromotor.

\subsection{Variation in Mechanical Properties}

Obviously, there will be changes in the mechanical properties of the produced specimen because of its variation in metallurgical structure. The following mechanical properties are tested for the weldments. 


\subsubsection{Flexural test}

The samples were tested for four point bending flexural test to find the flexural strength of welded joint. For conducting four point bend test, the dimensions of the specimen are taken according to ASTM E23. Specimens before and after testing are represented in Figs. 3(a) \& (b) respectively, and the variation of Flexural strength with respect to the chosen parameters is presented in Fig. 4.

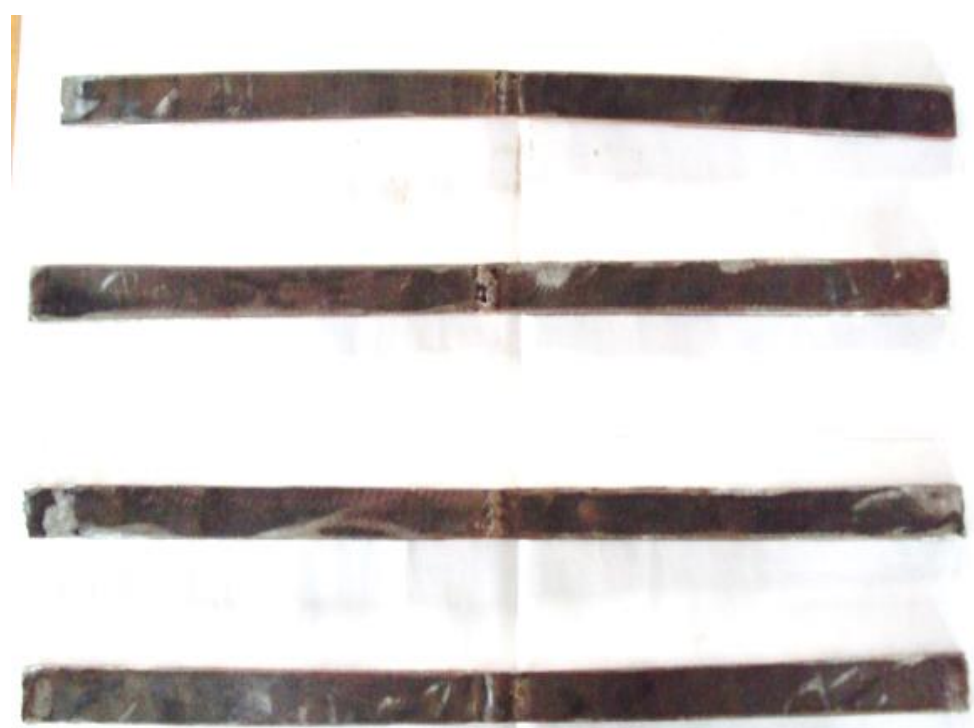

Fig. 3. (a) Produced specimens for Flexural test.

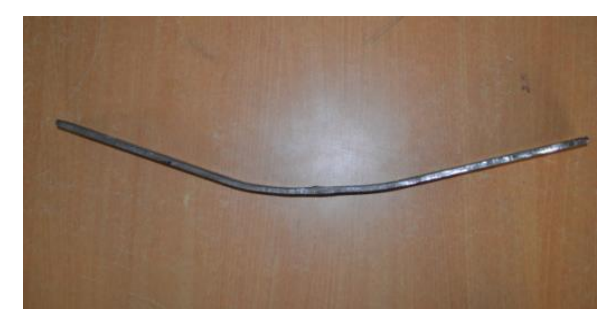

(i) At 0V, 100sec

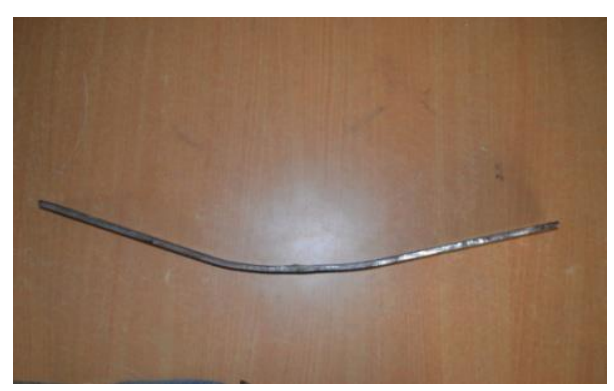

(iii) At 150V, 100sec

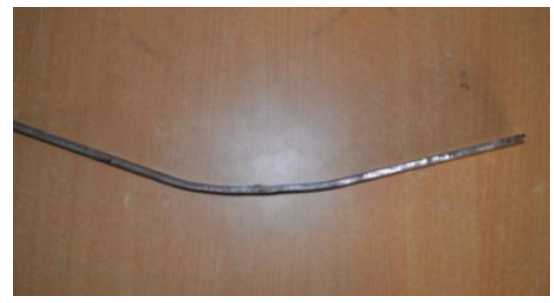

(ii) At 70V, 100sec

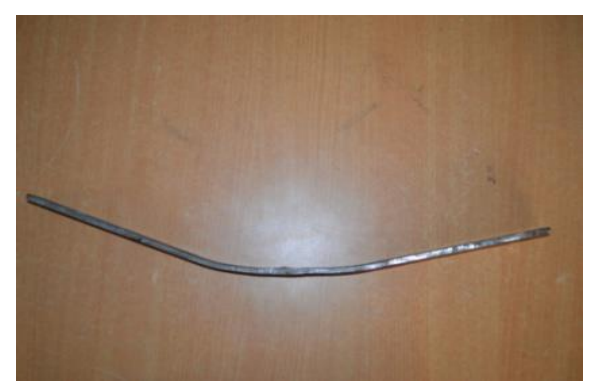

(iv) At 230V, 100sec

Fig. 3. (b) Specimens after Flexural failure. 


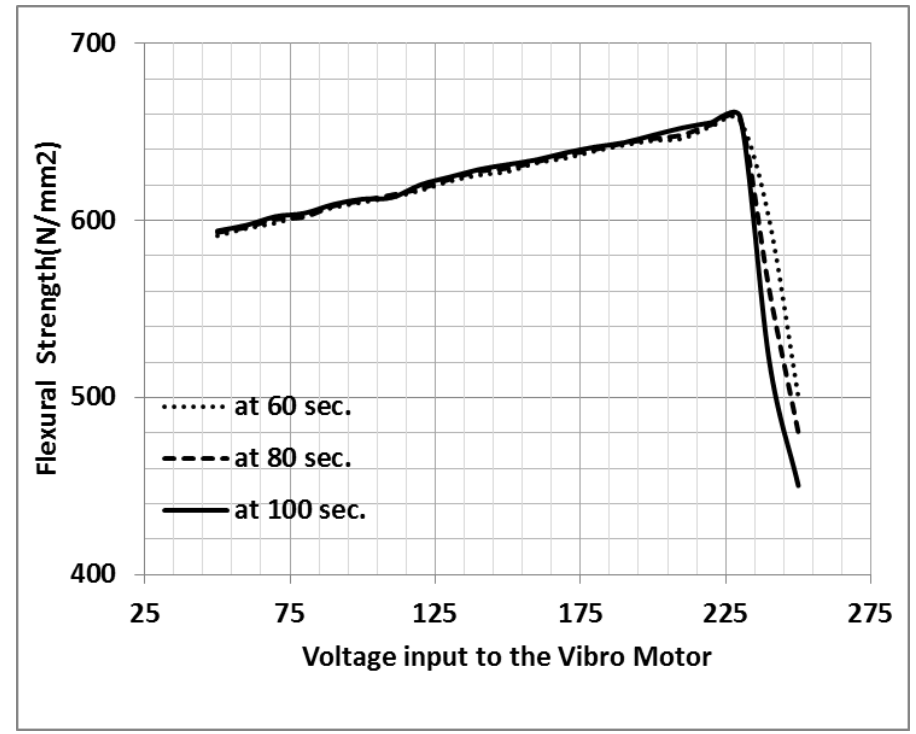

Fig. 4. Flexural strength variation with respect to input parameters.

\subsubsection{Impact test}

In the experimentation, Impact tests have been conducted on Charpy impact testing machine. The samples are prepared according to ASTM E23 standard and the notched specimen is placed as a simply supported beam and heavy pendulum is allowed to strike the specimen from a fixed height. The samples before and after testing are shown in Figs. 5 (a) \& (b) respectively. The variation in Impact strength at various input parameters is represented in Fig. 6.

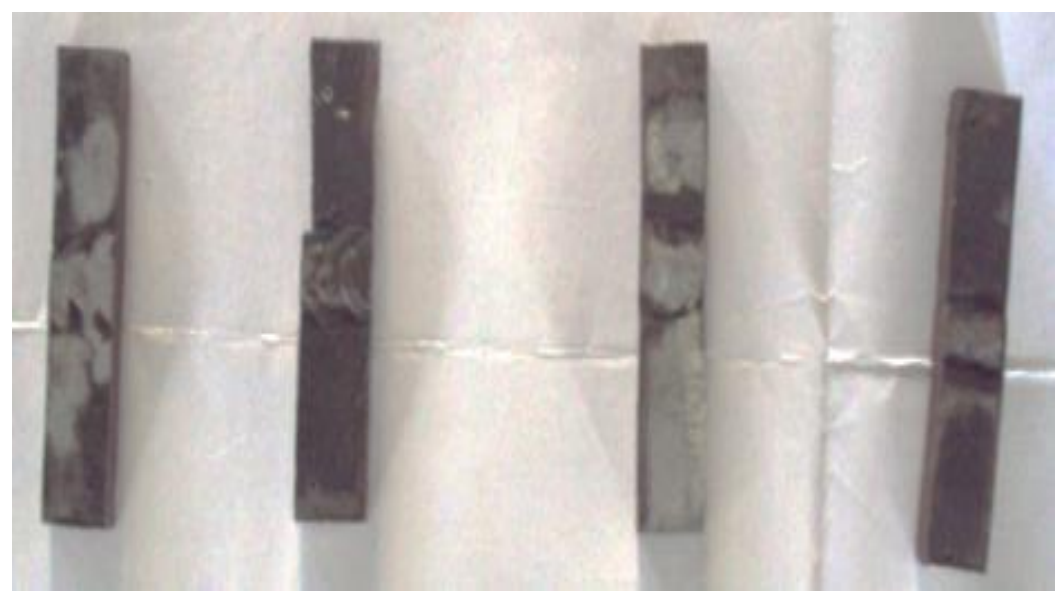

Fig. 5. (a) Specimen samples prepared at different vibration parameters for impact test.

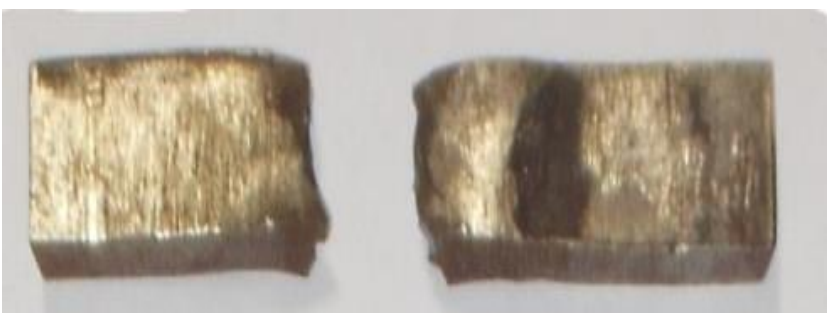

(i) At 0V, $100 \mathrm{sec}$

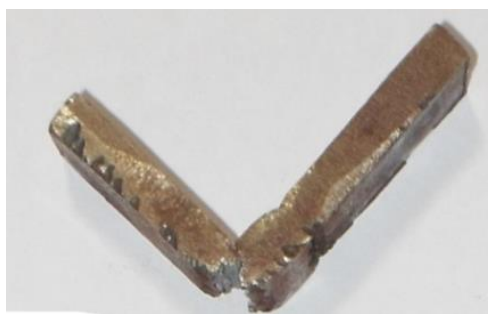

(ii) At 70V, $100 \mathrm{sec}$ 


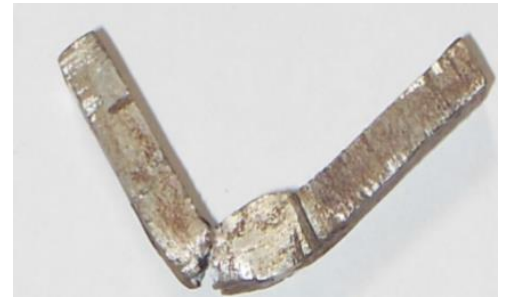

(iii) At 150V, $100 \mathrm{sec}$

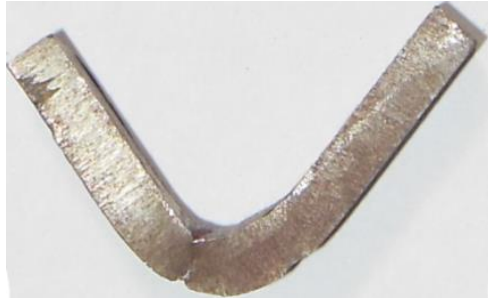

(iv) At 230V, $100 \mathrm{sec}$

Fig. 5. (b) Specimens after impact failure.

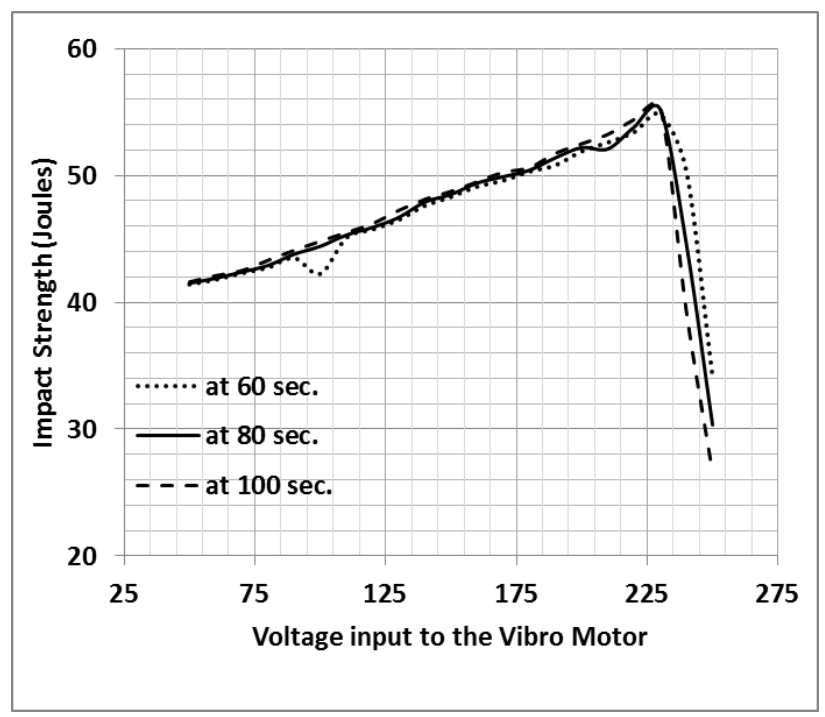

Fig. 6. Impact strength variation with respect to input parameters.

\section{Neural Network Based Prediction Tool}

It is observed that inputs $\left(\mathrm{X}_{\mathrm{i}}\right)$ and outputs $\left(\mathrm{Y}_{\mathrm{i}}\right)$ are showing non-linear nature and there is no specific relation between input and output. So, it is essential to obtain a relationship between input and output, thereby optimizing the input parameters.

GRNN (General Regression Neural Network) is one of the efficient regression method to estimate the output through the neural networks [30-31]. The structure of the GRNN consists of four layers namely: input, radial, regression and output layers. Input layer takes the all input values and these are supplied for clustering in the second layer. The third layer is with one extra neuron, which calculates the probability density function.The archetypal sketch of the proposed GRNN is represented in Fig. 7.

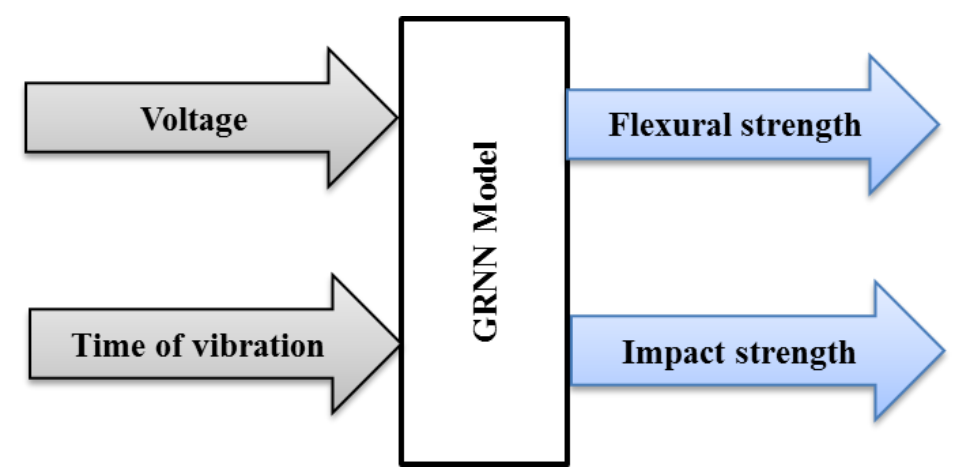

Fig. 7. Description of GRNN model. 
The GRNN based prediction tool is established with the use of experimental datasets. Vibrometer voltage and vibration period were considered as input and the mechanical properties: flexural and impact strength are pondered as output parameters. The proposed GRNN estimates the mechanical properties for any combination of voltage and time of vibration as represented in Fig. 8.

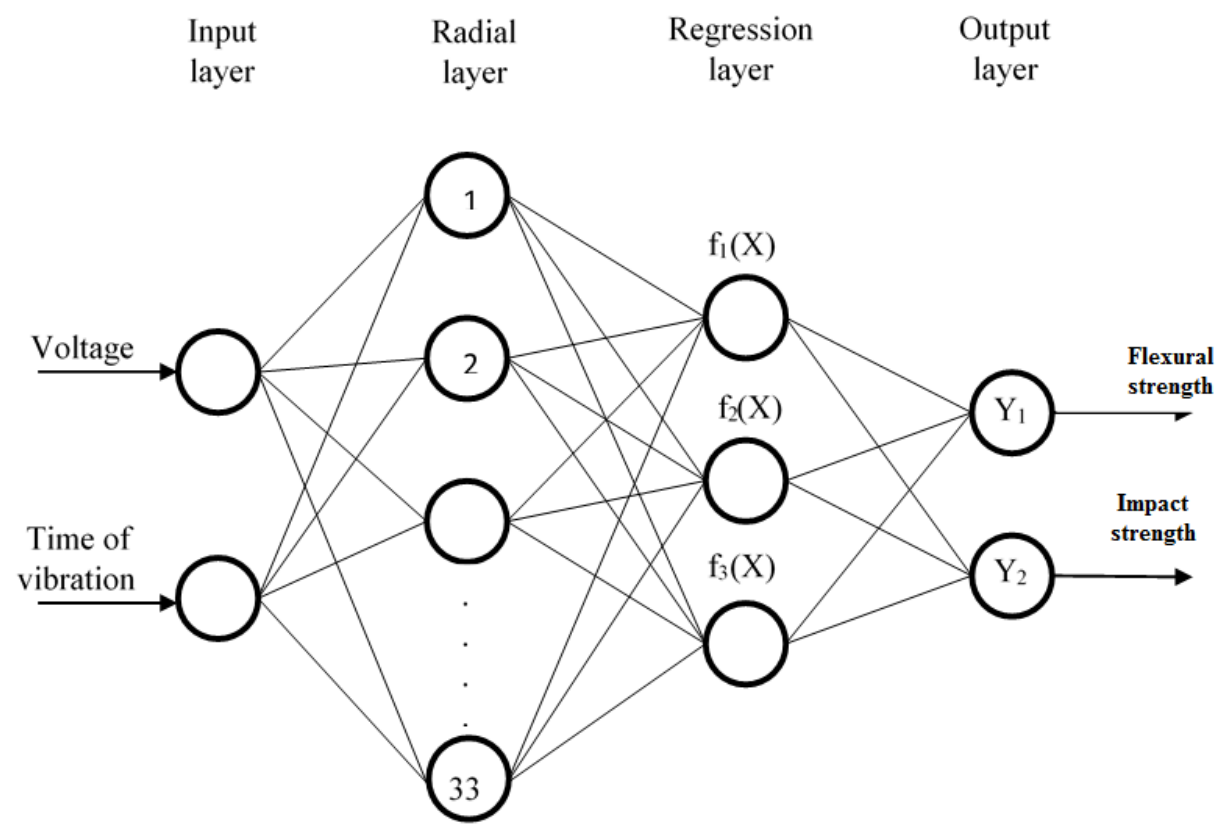

Fig. 8. GRNN architecture used for estimating mechanical properties.

The main feature of a probabilistic neural network is to generate the unknown function of the data with the help of few existing training samples. In order to obtain a relationship among these parameters, GRNN is implemented in this study. To implement GRNN prediction tool, more number of data-sets are required $(>40)$. Further increase in number of data-sets, improves the output accuracy. In the present study, "63" number of experimental data sets are considered. To obtain better relation between input and output, more number of data-sets are considered for tuning the relation (among them "33" are trainee data, "30" are tested and validation data i.e., 2:1:1). The proposed model estimates output values as a function of input values according to Eq. (1).

$$
\text { GRNN ouptu }\left(\mathrm{Y}_{\mathrm{GRNN}}\right)=\frac{\sum_{\mathrm{i}=1}^{33} \mathrm{Y}_{\mathrm{i}} \mathrm{e}^{\left(\mathrm{D}_{\mathrm{i}}{ }^{2} / 2 \sigma^{2}\right)}}{\sum_{\mathrm{i}=1}^{62} \mathrm{e}^{\left(\mathrm{D}_{\mathrm{i}}{ }^{2} / 2 \sigma^{2}\right)}}
$$

where ' $\sigma$ ' is smoothing parameter; $D_{i}^{2}=\left(X-X^{i}\right)^{T}\left(X-X^{i}\right)$.

\subsection{GRNN Cross-Validation}

Before processing the GRNN, cross validation is to be carried out to determine the optimal smoothening parameter $(\sigma)$ becausehigh values of $\sigma$ leads to over smoothening andthe lowweights of $\sigma$ leads to over fitting. In this investigation, a grid search method is applied to obtain the best Kernel width $(\sigma)$ for a range of $\sigma$ values [ $\sigma_{-}$min , $\left.\sigma_{-} \max \right]$ with ' $N$ ' number of iterations using Eq. (2).

$$
\sigma=\sigma_{\min }+(\mathrm{i}-1) \frac{\sigma_{\max }-\sigma_{\min }}{\mathrm{N}} \text { for } \mathrm{i}=1,2, \ldots, \mathrm{N}
$$

From the graph as shown in Fig. 9, it is clear that the optimal Kernel band width with minimum cross validation is obtained at 3.73 . 


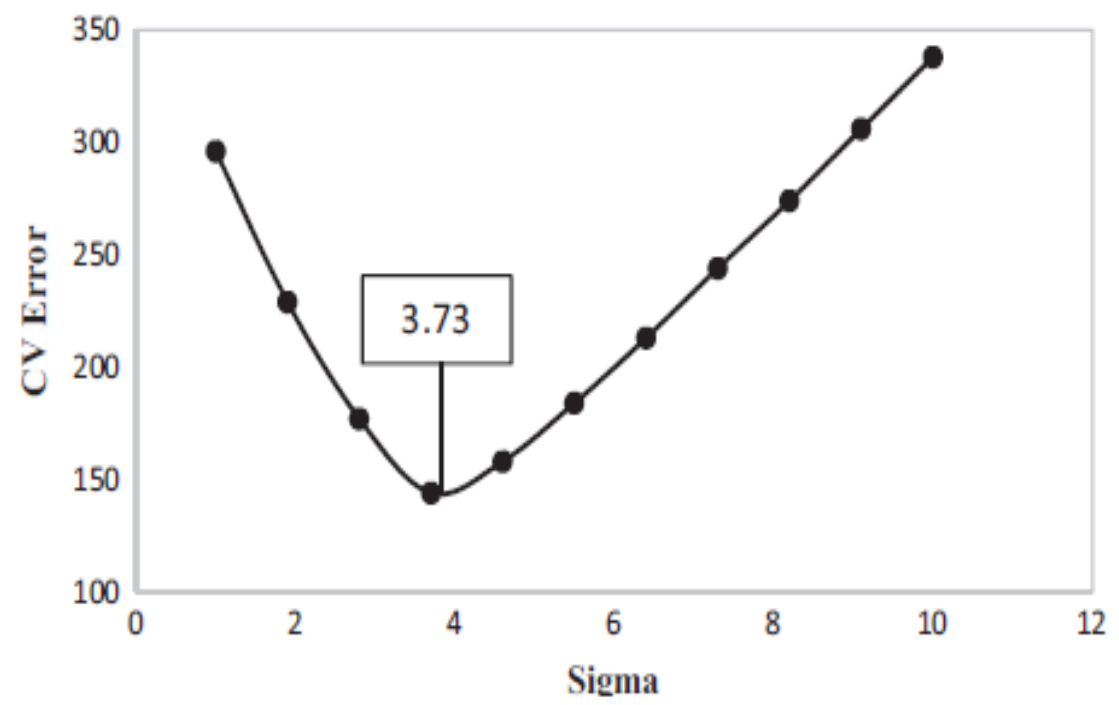

Fig. 9. Cross-validation graph for finding optimal kernel width.

The established model is tested and found that the results are matched with the experimental values. Figures 10-11 represent the variation of GRNN output values with respect to the experimental output values for the trainee, test and validation datasets. It is obvious from the figures that a maximum of $5 \%$ error observed during GRNN validation. The main purpose of the proposed model is to estimate the mechanical properties for the given input values (voltage and time of vibration). The benefit of this research work is, without performing the experiments, output values can be predicted for the given input values.

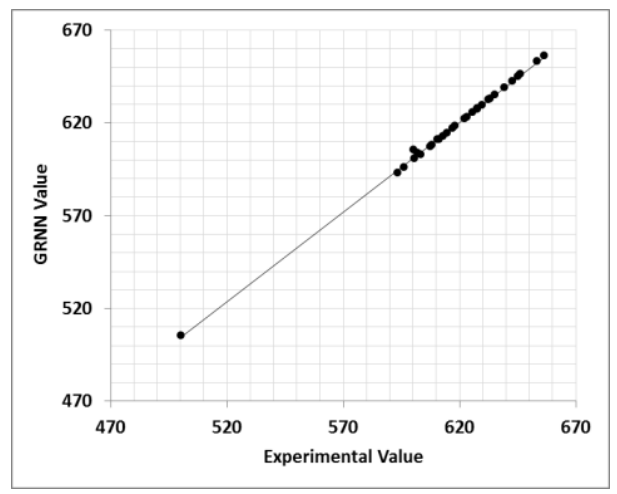

(a) Trainee datasets.

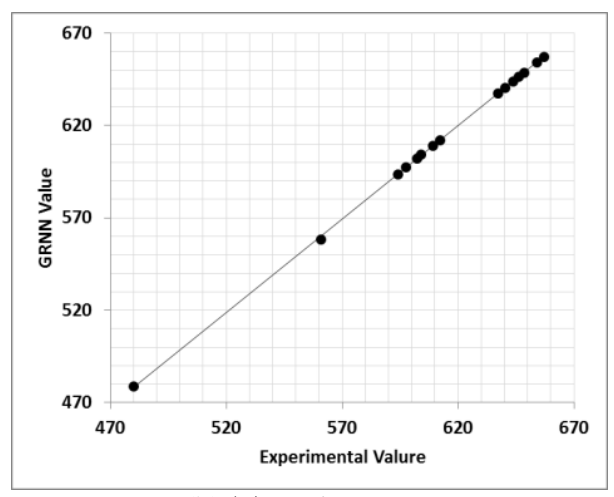

(b) Test datasets.

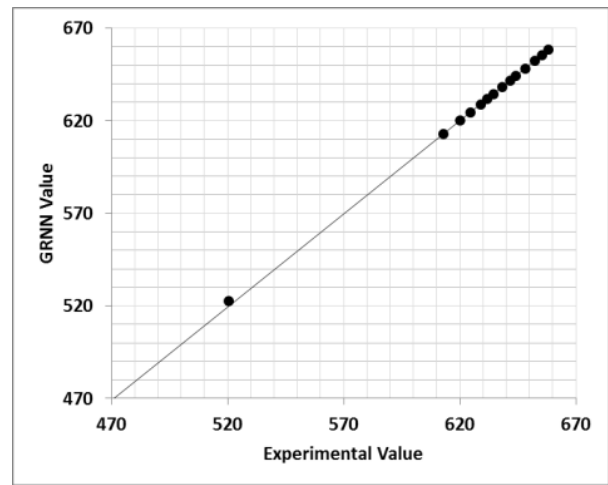

(c) Validation datasets.

Fig. 10. Deviation of actual Flexuralstrength property (Y1) from GRNN estimation. 


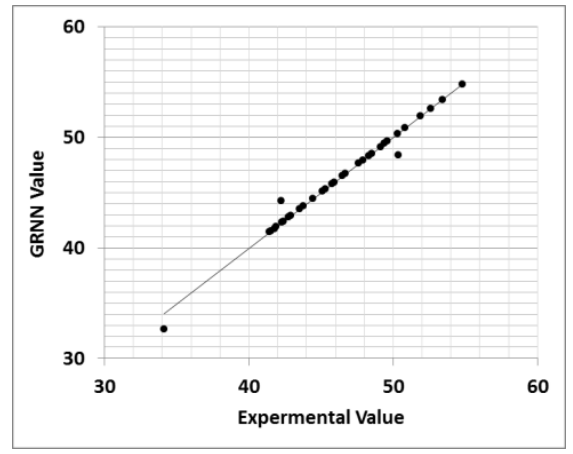

(a) Trainee datasets.

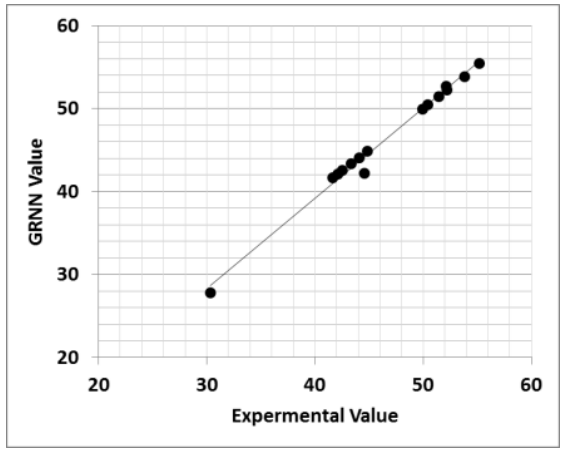

(b) Test datasets.

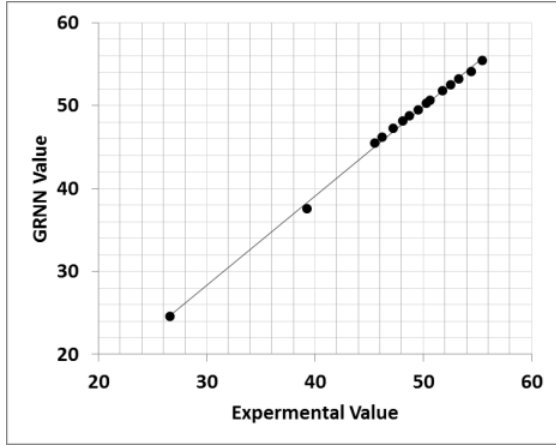

(c) Validation datasets.

Fig. 11. Deviation of actual Impact strength property (Y2) from GRNN estimation.

The proposed GRNN tool is a good add-on for estimating the mechanical properties for the given input values. But, this model is silent about the optimized input parameters to produce quality welded joints. Therefore, it is necessary to implement an adaptive mechanism to the developed GRNN method in order to find out the optimized input parameters for producing welded joints with desired weld quality.

\section{GRNN-Axis for Optimal Mechanical Properties}

Generally, human immune system defends the body by generating appropriate antibodies once it happenstances any sort of intruders [32]. Following possessions of the immune scheme are of prodigious curiosity for researchers:

- Uniqueness: every particle has its own immune structure.

- Gratitude of Strangers: the antigens are documented and eradicated from body.

- Anomaly Detection: the immune system can detect and react to pathogens that the body has never encountered before;

- Noise Lenience: the system is supple because the prediction of the antigens is not obligatory.

- Reinforcement Learning and Memory: forthcoming replies to the same pathogens are quicker and sturdier since the immune scheme can "learn" the buildings of invaders.

\subsection{Basic Immune Models and Algorithms}

There are several immune models developed to resolve numerous engineering snags [33]. Below are the some of the immune based techniques:

- Bone Marrow Replicas

- Negative Selection

- Clonal Selection

- Somatic Hyper-mutation

- Immune Network Theory

In this investigation, Bone Marrow Replicas and Negative Selection Algorithms have been implemented for generating optimal-feasible input sequence. The immune models of the bone marrow and the Negative Selection are as follows: 
Bone marrow replicas [34]: these models generate the suitable antibodies as shown in Fig. 12. Immune system contains particular proteins in the gene-libraries. An antibody will be generated by combining the specific segment from each of the gene-library. Because of its Reinforcement Learning and Memory nature, immune system can remember the structure of each antibody.

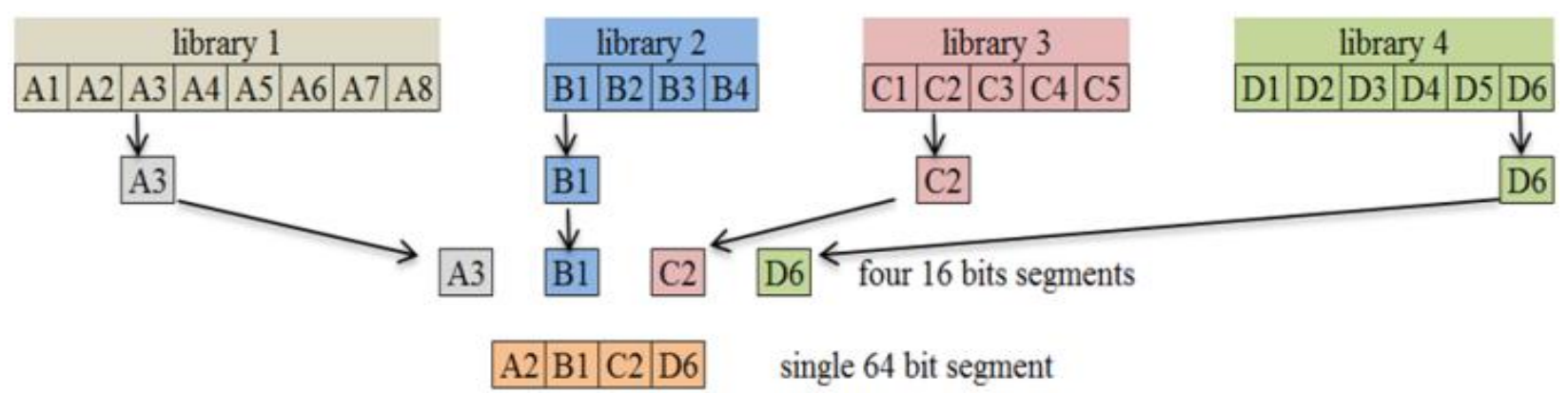

Fig. 12. Antibody production through a random concatenation from gene libraries.

Negative selection Model [35]: This notion is inspired from the deleterious assortment of T-cells in the thymus as represented in Fig. 13. This algorithm is useful for producing new antibody string when the previous antibodies are not suitable for neutralizing the detected antigens.

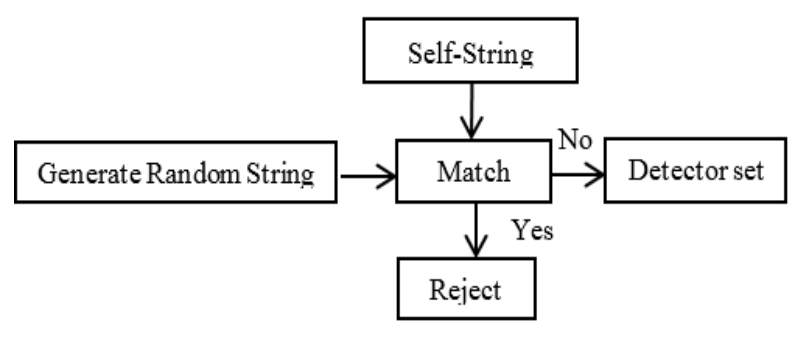

(a) Censoring model.

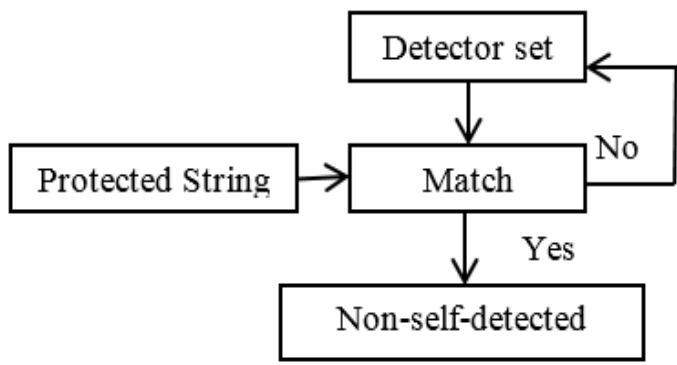

(b) Monitoring model.

Fig. 13. Negative selection algorithm censoring \& monitoring.

\subsection{Immune Based Input Generation}

The production of antibodies using bone marrow models can be implemented here for generating input string which is to be supplied to GRNN in the following steps:

Step 1: Consider the number of input parameters is equal to the number of gene-libraries (inputlibraries). Therefore 2 input-libraries correspond to 2 input parameters.

\begin{tabular}{|l|l|}
\hline $\mathrm{X} 1$ & $\mathrm{X} 2$ \\
\hline
\end{tabular}

Step 2: Consider an antibody (input string) with ' 2 ' empty segments and number them from 1 to ' 7 '.

$$
\begin{array}{|l|l|}
\hline \multicolumn{2}{|l|}{\text { Initial antibody structure }} \\
\hline \mathrm{X} 1 & \mathrm{X} 2 \\
\hline
\end{array}
$$

Step 3: Combine the specific segment from each of the gene-library corresponds to the antibody allocation. Then check for the each input boundary as follows:

$$
\begin{aligned}
& 60 \leq \mathrm{X} 2 \geq 100 \\
& 50 \leq \mathrm{X} 3 \geq 250
\end{aligned}
$$


Step 4: Apply reinforcement learning to the system in order to avoid the generation of same antibody strings.

Step 5: Send the generated antibody to negative selection model for checking its affinity strength and feasibility.

\subsection{Calculation of Antibody Concentration (Fitness Function)}

From the observed data, it is clear that the heat transfer and the overall pressure drop are increasing with respect to the Reynolds number. But an optimized vibratory welding system gives more flexural and impact strength. Therefore, it is required to optimize the input process parameters to satisfy the below two criteria. To attain the optimized parameters, some sort of objective function is to be developed while satisfying the input constraints [36, 37].

The developed fitness function should attain the maximum Flexural strength (Fs).

$$
\Rightarrow \mathrm{F} \propto \mathrm{F}_{\mathrm{S}}
$$

The developed fitness function should attain the maximum Impact Strength (IS).

$$
\Rightarrow \mathrm{F} \propto \mathrm{I}_{\mathrm{S}}
$$

From Eq. (3) \& (4), the final form of the fitness function is represented in Eq. (5).

$$
\mathrm{F}=\mathrm{k}_{1} \mathrm{~F}_{\mathrm{s}}+\mathrm{k}_{2} \mathrm{I}_{\mathrm{s}}
$$

where $\mathrm{k}_{1} \& \mathrm{k}_{2}$ are weights correspond to flexural and impact strength. In this investigation, these values are considered as $\mathrm{k}_{1}=5.61 \& \mathrm{k}_{2}=39.96$ in order to normalize the fitness value corresponds to flexural and impact strength. These weights are determined from the experimental datasets: $\mathrm{k}_{1}$ corresponds to the standard deviation of impact strengths and $\mathrm{k}_{2}$ corresponds to the standard deviation of flexural.

\subsection{Negative Selection for Obtaining Optimal Criteria}

Once an antibody generated from the developed bone marrow model, it will be sent to GRNN prediction tool for estimating the output values as discussed in the previous chapter.

In this investigation, two negative selection algorithms namely Censoring Model and Monitoring Model have been implemented. Censoring Model checks the input boundaries for the generated antibody and gives the feasible sequence as shown in Fig. 14.

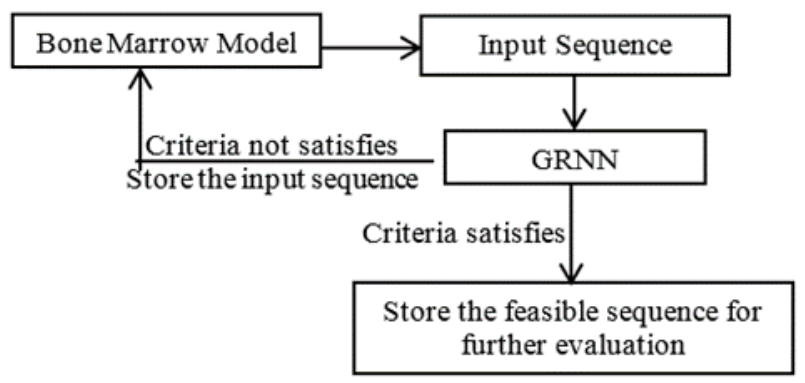

Fig. 14. Censoring Model for obtaining feasible sequences.

\subsubsection{Monitoring model for obtaining OFS}

Among the obtained feasible sequences (antibodies), fitness for each sequence is to be calculated to find an OFS. For this purpose, an immune model has been developed in this research work, which measures the antibody concentration (fitness function) for the feasible sequences obtained from bone marrow model. The detailed diagrammatic view of obtaining OFS using negative selection monitoring model is represented in Fig. 15. 


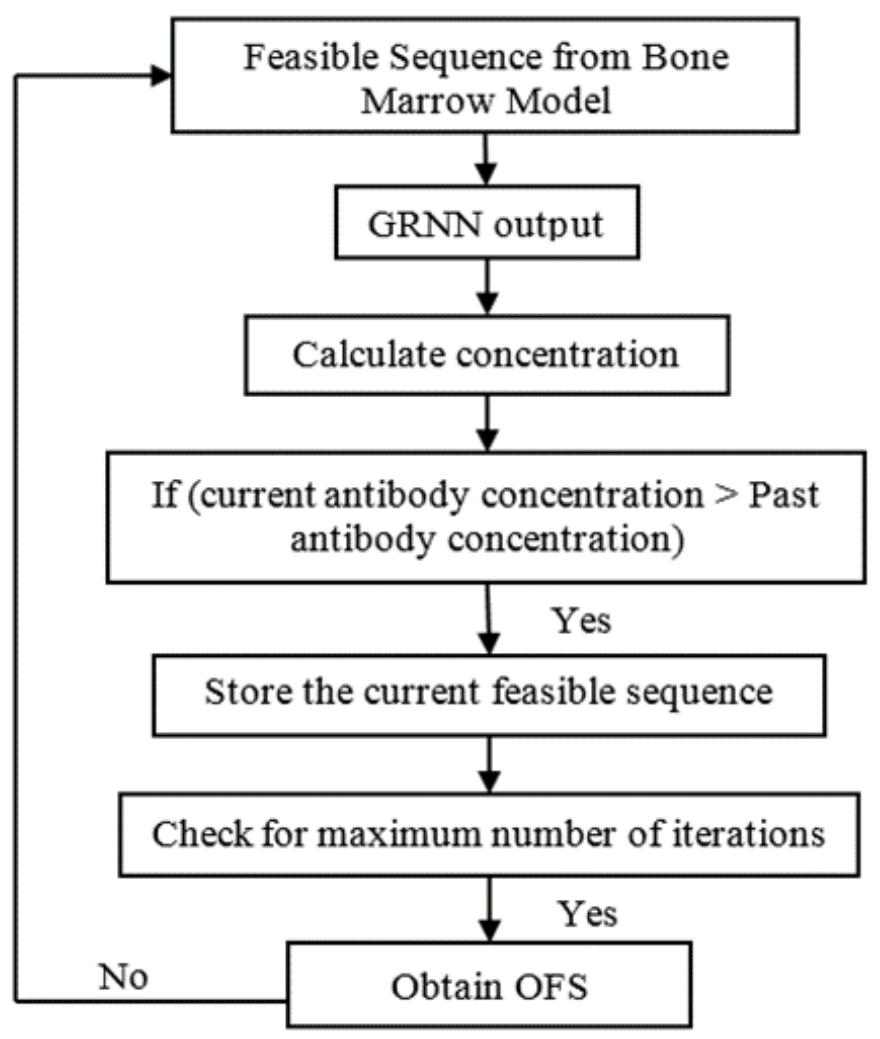

Fig. 15. Monitoring Model for obtaining OFS.

\section{Results \& Discussion}

The developed methodology for obtaining an OFS has been implemented for the vibratory assisted welding operation. This structure consists of 2 inputs labeled with X1 to X2. Bone marrow model produces possible antibodies as discussed in section 5.2. Then each of the input sequence is to be checked for its feasibility with the help of negative selection censor model.

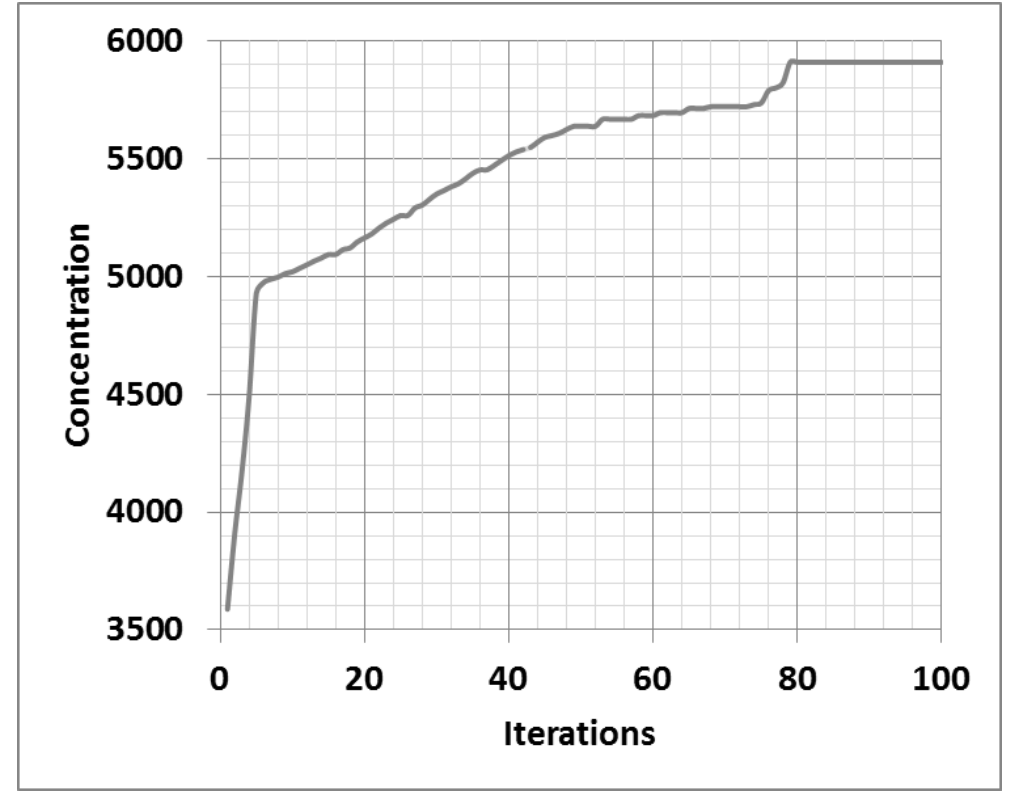

Fig. 16. Fitness variation for 100 cycles. 
While implementing the developed (general regression neural network-artificial immune based strategy) GRNN-AIS model, the system is converged at $79^{\text {th }}$ iteration with antibody concentration (fitness value) 5913.065 as shown in Fig. 16. The detailed analysis results are illustrated in Table 2.

Table 2. Analysis results for the developed GRNN-AIS model.

\begin{tabular}{llll}
\hline Iteration no. & Input values & GRNN output values & Fitness value \\
\hline \multirow{2}{*}{79} & $\mathrm{X} 1=228$ & Y1 $=658.34$ & \multirow{2}{*}{5913.065} \\
& $\mathrm{X} 2=98$ & $\mathrm{Y} 2=55.55$ & \\
\hline
\end{tabular}

\section{Conclusion}

The developed GRNN tool is very much loftier in estimating the output values with $\pm 5 \%$ error. The main purpose of the proposed model is to estimate the mechanical properties of the welded joints for the given input values (voltage and vibration period). The benefit of this research work is, without performing the experiments output values can be predicted for the given input values. Developed immune architecture generates the optimized input parameters, which satisfies the criteria maximum flexural and impact strength. From the developed hybrid GRNN-AIS system, it is clear that the vibratory welding system produces the quality welded joints at 228 volts with a vibration period $98 \mathrm{sec}$.

\section{References}

[1] B. B. V. L. Deepak, C. A. Rao, and B. M. V. A. Raju, "Weld seam tracking and simulation of 3-axis robotic arm for performing welding operation in CAD environment, CAD/CAM, robotics and factories of the future," in Lecture Notes in Mechanical Engineering, D. K. Mandal and C. S. Syan, Eds. India: Springer, 2016, pp. 405-415.

[2] J. Ding, D. Wang, Y. Wang, and H. Du, "Effect of post weld treatment on properties of variable polarity TIG welded AA2219 aluminium alloy joints," Transactions of Nonferrous Metals Society of China, vol. 24, pp. 1302-1316, 2014.

[3] S. Riyaz Ahmed, A. Agarwal, and B. S. S. Daniel, "Effect of different post weld heat treatment on the mechanical properties of Cr-Mo boiler steel welded with SMAW process," Materials Today: Proceedings, vol. 2, no. 4-5, pp. 1059-1066, 2015.

[4] T. Ibrahim, D. S. Yawas, and Y. Aku, "Effect of gas metal arc welding technique on the mechanical properties of duplex stainless steel," Journal of Minerals and Materials Characterization and Engineering, vol. 1, pp. 222-230, 2013.

[5] R. Ahmad and M. A. Bakar, "Effect of a post-weld heat treatment on the mechanical and microstructure properties of AA6061 joints welded by the gas metal arc welding cold metal transfer method," Materials and Design, vol. 32, no. 10, pp. 5120-5126, 2011.

[6] Z. Y. Zhu, C. Y. Deng, Y. Wang, Z. W. Yang, J. K. Ding, and D. P. Wang, "Effect of post weld heat treatment on the microstructure and corrosion behavior of AA2219 aluminum alloy joints welded by variable polarity tungsten inert gas welding," Materials and Design, vol. 65, pp. 1075-1082, 2015.

[7] C. Smith and C. Pistorius, "The effect of along post weld heat treatment on the integrity of a welded joint in a pressure vessel steel," International Journal of Pressure Vessels and Piping, vol. 70, pp. 183-195, 1997.

[8] R. Badji, B. Belkessa, H. Maza, M. Bouabdllah, and C. Kahloun, "Effect of post weld heat treatment on microstructure and mechanical properties of welded 2025 duplex stainless steel," Materials Science Forum, vol. 467-470, pp. 217-222, 2004.

[9] J. W. Mao, W. J. Lu, L. Q. Wang, D. Zhang, and J. N. Qin, "Microstructure and mechanical properties of GTA weldments of titanium matrix composites prepared with or without current pulsing," Transactions of Nonferrous Metals Society of China, vol. 24, pp. 1393-1399, 2014.

[10] C. Sawanishi, T. Ogura, K. Taniguchi, R. Ikeda, K. Oi, K. Yasuda, and A. Hirose, "Mechanical properties and microstructures of resistance spot welded DP980 steel joints using pulsed current pattern," Science and Technology of Welding and Joining, vol. 19, no. 1, pp. 52-59, 2014. 
[11] V. Balasubramanian, V. Ravisankar, and G. M. Reddy, "Effect of pulsed current welding on mechanical properties of high strength aluminum alloy," Int. J. Adv. Manuf. Technol., vol. 36, pp. 254 262, 2008.

[12] M. Manikandan, N. Arivazhagan, M. Nageswararao, and G. M. Reddy, "Microstructure and mechanical properties of alloy C-276 weldments fabricated by continuous and pulsed current gas tunston arc welding techniques," Journal of Manufacturing Processes, vol. 16, pp. 563-572, 2014.

[13] A. Ravindra and B. V. R. Ravi Kumar, "Experimental study on pulsed current TIG welding of stainless steel sheet (SS304)," International Journal of Innovative Research in Science Engineering and Technology, vol. 2, no. 6, pp. 2337-2344, (2013).

[14] X. Dai, H. Zhang, J. Liu, and J. Feng, "Microstructure and properties of Mg/Al joint welded by gas tungsten arc welding-assisted hybrid ultrasonic seam welding," Materials \& Design, vol. 77, pp. 65-71, 2015.

[15] P. Leo, G. Renna, G. Casalino, and A. G. Olabi, "Effect of power distribution on the weld quality during hybrid laser welding of an Al-Mg alloy," Optics \& Laser Technology, vol. 73, pp. 118-126, 2015.

[16] C. Li and L. Liu, "Investigation on weldability of magnesium alloy thin sheet T-joints: arc welding, laser welding, and laser-arc hybrid welding," The International Journal of Advanced Manufacturing Technology, vol. 65, no. 1-4, pp. 27-34, 2013.

[17] I. F. Goncharevich, K. V. Frolov, and E. I. Rivin, Theory of Vibratory Technology. New York: Hemisphere Publishing Corporation, 1990, pp. 163-177.

[18] L. Qinghua, C. Ligong, and N. Chunzhen, "Effect of vibratory weld conditioning on welded valve properties," Mechanics of Materials, vol. 40, pp. 565-574, 2008.

[19] P. Govinda Rao, P. Srinivasa Rao, and A. Gopala Krishna, "Mechanical properties improvement of weldments using vibratory welding system," Proceedings of the Institution of Mechanical Engineers, Part B: Journal of Engineering Manufacture, vol. 229, no. 5, pp. 776-784, May 2015.

[20] P. Govinda Rao, P. Srinivasa Rao, and A. Gopala Krishna, "A smart prediction tool for estimating impact strength of welded joints prepared by vibratory welding process," Proceedings of the Institution of Mechanical Engineers, Part E: Journal of Process Mechanical Engineering, vol. 231, no. 2, pp. 343-346, 2017.

[21] P. Govinda Rao, P. Srinivasa Rao, and A. Gopala Krishna, "Evaluation of bending strength of the vibratory welded joint using regression technique," International Journal of Offshore and Polar Engineering, vol. 25, no. 3, pp. 227-230, Sept. 2015.

[22] P. Govinda Rao, P. Srinivasa Rao, A. Gopalakrishna, and M. M. M. Sarkar, "Affect of vibratory welding process to improve the mechanical properties of butt welded joints," International Journal of Modern Engineering Research, vol. 2, no. 2, pp. 2766-2770, 2012.

[23] P. Govinda Rao, P. Srinivasa Rao, and A. Gopala Krishna, "Impact strength improvement of butt welded joints prepared by vibratory welding process," Journal of Manufacturing Technology Research, vol. 6, no. 3-4, pp. 143-151, 2015.

[24] P. Govinda Rao, P. Srinivasa Rao, and A. Gopala Krishna, "Review on residual stresses in welded joints prepared under the influence of mechanical vibrations," Journal of Manufacturing Technology Research, vol. 6, no. 1-2, pp. 33-40, 2014.

[25] P. Govinda Rao, P. Srinivasa Rao, and A. Gopala Krishna, "Flexural strength improvement of welded joints prepared by vibratory welding process," International Journal of Manufacturing, Materials, and Mechanical Engineering, vol. 5, no. 4, pp. 1-16, 2015.

[26] P. Govinda Rao, P. Srinivasa Rao, A. Gopala Krishna, and C. V. Sriram, "Improvement of tensile strength of a butt welded joints prepared by vibratory welding process," International Journal of Mechanical Engineering and Technology, vol. 4, no. 2, pp. 53-61, 2013.

[27] P. Govinda Rao, C. L. V. R. S. V. Prasad, D. Sriramulu, V. Chittibabu, and M. Vykunta Rao, "Determination of residual stresses of welded joints prepared under the influence of mechanical vibrations by hole drilling method and compared by finite element analysis," International Journal of Mechanical Engineering and Technology, vol. 4, no. 2, pp. 542-553, 2013.

[28] P. Govinda Rao, C. L. V. R. S. V. Prasad, S. V. Ramana, and D. Sreeramulu, "Development of GRNN based tool for hardness measurement of homogeneous welded joint under vibratory weld condition," International Journal of Advanced Research in Engineering and Technology, vol. 4, no. 4, pp. 50-59, 2013.

[29] J. Kalpana, P. S. Rao, and P. G. Rao, "Influence of amplitude on the tensile strength of welded joints fabricated under vibratory weld conditioning," Journal Mechanical Engineering Research Developments, vol. 39, no. 3, pp. 757-762, 2016. 
[30] B. Harisankar, B. B. V. L. Deepak, and S. Murugana, "Application of GRNN for the prediction of performance and exhaust emissions in HCCI engine using ethanol," Energy Conversion and Management, vol. 122, pp. 145-153, 2016.

[31] J. B. B. Rao, V. R. Raju, and B. B. V. L. Deepak, "A smart prediction tool for estimating heat transfer and pressure drop," International Journal of Current Research in Engineering, Science and Technology, vol. 1, no. 1, pp. 17-22, 2016.

[32] B. B. V. L. Deepak, D. R. Parhi, and S. Kundu, "Innate immune based path planner of an autonomous mobile robot," Procedia Engineering, vol. 38, pp. 2663-2671, 2012.

[33] B. B. V. L. Deepak and D. Parhi, "Control of an automated mobile manipulator using artificial immune system," Journal of Experimental \& Theoretical Artificial Intelligence, vol. 28, no. 1-2, pp. 417-439, 2016.

[34] B. B. V. L. Deepak and D. Parhi, "Intelligent adaptive immune-based motion planner of a mobile robot in cluttered environment," Intelligent Service Robotics, vol. 6, no. 3, pp. 155-162, 2013.

[35] M. V. A. Raju Bahubalendruni, B. B. V. L. Deepak, and B. B. Biswal, "An advanced immune based strategy to obtain an optimal feasible assembly sequence," Assembly Automation, vol. 36, no. 2, pp. 127137, 2016.

[36] B. B. V. L. Deepak, D. R. Parhi, and B. M. V. A. Raju, "Advance particle swarm optimization based navigational controller for mobile robot," Arabian Journal for Science and Engineering, vol. 39, no. 8, pp. 6477-6487, 2014.

[37] B. B. V. L. Deepak and D. R. Parhi, "Target seeking behaviour of an intelligent mobile robot using advanced particle swarm optimization," in IEEE International Conference on Control, Automation, Robotics and Embedded Systems, 2013, pp. 1-6. 